\author{
W. Szymański, M. Lech-Grega
}

Institute of Non-Ferrous Metals Light Metals Division, Skawina, Poland

wszymanski@imn.skawina.pl

\title{
VALIDATION OF THE X-RAY STRESS MEASUREMENT METHOD
}

\begin{abstract}
One of the most important characteristics of the material allowing us to predict its applicability for specific tasks as a single object or as an integral part of the whole structure is the presence of stresses. There are many methods to measure stress. Among them, increasingly important and recognised as the most accurate non-destructive method is the X-ray measurement technique. The aim of this study was validation of the results obtained by the $\mathrm{X}$-ray stress measurement method. Stress measurements were performed on samples of the three materials subjected during measurement to the effect of tensile forces. Studies revealed close relationship between the stress values measured by X-ray technique and actual values present in the examined material. The summation of residual stresses present in the material and stresses caused by the effect of external forces was observed.
\end{abstract}

Key words: stress measurement, residual stress, $X$-ray stress measurement

\section{INTRODUCTION}

There are many methods to measure stress, and they fall into two main categories, i.e. the destructive methods and the non-destructive ones. Currently, the most important are the nondestructive methods - the fact quite obvious and easy to understand. In the latter group, the most popular are the methods of magnetic inspection and X-ray technique [1].

Magnetic methods rely on the measurement of changes in the magnetisation curve resulting from the effect exerted by local stress centres on the value and the amplitude of magnetic oscillations. One of these methods is used for the measurement of magnetic Barkhausen noise. It is based on the evaluation of magnetic noise which arises when the magnetic domain walls are abruptly pushed by stress accompanied by the effect of external magnetic field. With the help of proper instrument, using this method, one can measure stresses in a relatively short time even in objects varying in size [2].

$\mathrm{X}$-ray methods measure changes in the interplanar distance. Under the impact of load resulting in deformation of the examined material, a displacement of components of the crystal lattice structure occurs. Changes in the interplanar spacing $d_{\mathrm{hkl}}$ can be a measure of stress, and this is the main principle on which the X-ray methods are based [3, 4].

Currently, in the group of X-ray methods, the most widely used is the $\sin ^{2} \psi$ method. It is realized using X-ray diffractometer. The essence of the method is to determine variations in interplanar distances in the crystal lattice of the material under the influence of forces occurring therein.

Historically, the primary drawback of this method was considered to be the need for cutting out small specimens to fit the traditional goniometers, which obviously had to cause some changes in the state of stress in the examined material. Now, with the use of modern 
diffractometers, it is possible to measure stress in objects of practically any size and identify the state of stress not relaxed by excision of the specimen.

Compared to magnetic methods, the measurements by X-ray technique take longer time and measure stress in a layer of the thickness of about 10-20 $\mu \mathrm{m}$, i.e. ten times shallower than the one used in magnetic inspection. On the other hand, the advantage of the X-ray method is that it requires no reference standards; what is required is the knowledge of material constants such as Young's modulus and Poisson's ratio. Stresses are measured in a particular direction, thus enabling the determination of a stress tensor.

The X-ray methods of stress measurement have been known for years, but never enjoyed great popularity, especially in industry, since the results obtained are not trusted, being rather difficult in interpretation.

For many years, the Institute of Non-Ferrous Metals, Light Metals Division Skawina, studies stresses by the X-ray technique. These are both research [5-10] and application works allowing, for example, verification of the applied technology or product control [11-13]. Recently, widespread popularity are gaining stress measurements supplying data necessary for the development of mathematical models of various technological processes [14].

The aim of this study was to demonstrate a relationship between the stresses measured by $\mathrm{X}$-ray method and stresses actually present in the examined material.

\section{EQUIPMENT}

Residual stresses were measured with X-ray instruments used for the measurement of stress and retained austenite content:

- "Strainflex PSF 2M" made by Rigaku, Japan (Fig. 1),

- $\quad$ "PROTO iXRD" made by Proto, Canada (Fig. 2).

Both are portable X-ray diffractometers, fully computerized, used only for the measurement of residual stresses and retained austenite content. All instrument- and materialrelated parameters for the measurement of tensile specimens are shown in Table 1.

All specimens were subjected to the effect of constant tensile forces, using for this purpose either a specially designed machine for testing of small specimens or an Instron 5582 testing machine. On loaded specimens, stresses were measured by the X-ray technique (Figs. 3 and 4). The results of measurements are illustrated by graphs shown in Figures 5-9.

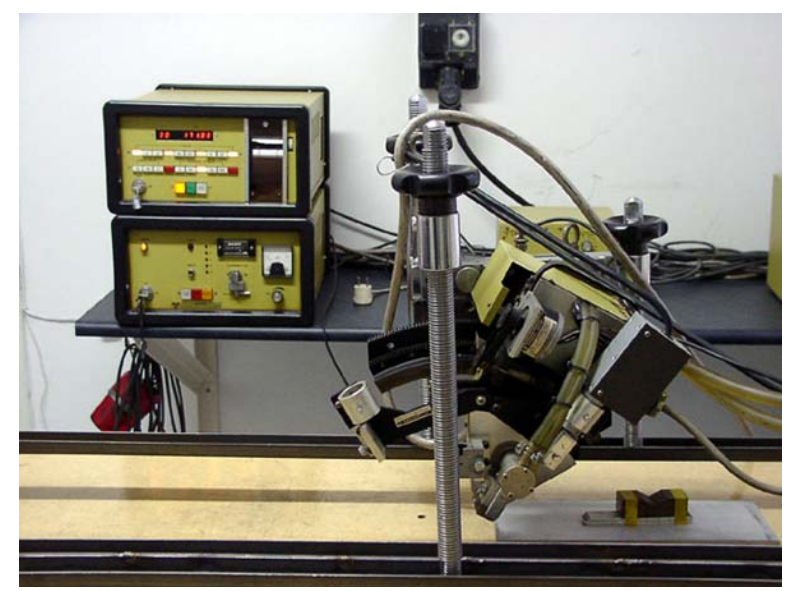

Fig. 1. Strainflex PSF $2 M$ apparatus for the measurement of residual stresses and retained austenite content 


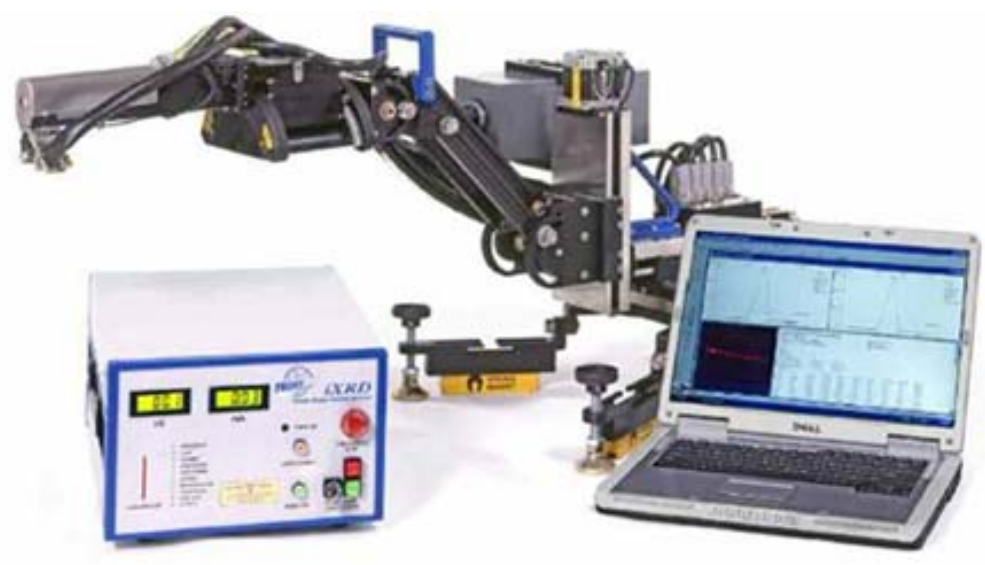

Fig. 2. PROTO IXRD X-ray diffractometer for the measurement of residual stresses and retained austenite content

Table 1. Measurement conditions

\begin{tabular}{|c|c|c|c|}
\hline $\begin{array}{c}\text { Apparatus for X-ray } \\
\text { measurement of residual } \\
\text { stresses }\end{array}$ & & $\begin{array}{l}\text { "STRAINFLAX-PSF 2M" } \\
\text { made by Rigaku - Japan }\end{array}$ & PROTO iXRD \\
\hline Voltage & & $30 \mathrm{kV}$ & $20 \mathrm{kV}$ \\
\hline Current in tube & & $5 \mathrm{~mA}$ & $4 \mathrm{~mA}$ \\
\hline Type of X-ray tube & & $\mathrm{Cr}$ & $\mathrm{Cr}$ \\
\hline Radiation length $\lambda \mathrm{Cr}$ & & $2.103[\AA]$ & $2.103[\AA]$ \\
\hline Planes of reflection & & $\begin{array}{c}222 \text { for } \mathrm{Al} \\
\text { and } 211 \text { for } \mathrm{Fe}\end{array}$ & Fe 211 \\
\hline $\begin{array}{l}\text { Measured angular range } \\
2 \theta\end{array}$ & & $140^{\circ}-170^{\circ}$ & $145^{\circ}-165^{\circ}$ \\
\hline $\begin{array}{l}\text { Size of X-ray beam } \\
\text { incident on sample }\end{array}$ & & $4 \times 2 \mathrm{~mm}$ & $5 \times 1 \mathrm{~mm}$ \\
\hline Tested material & & $\mathrm{Al}, \mathrm{Fe}$ & Ferritic steel \\
\hline $\begin{array}{c}\text { Bragg angle in } \\
\text { unstressed material } 2 \theta 0\end{array}$ & & $156.7^{\circ}$ for $\mathrm{Al}, 156.08^{\circ}$ for $\mathrm{Fe}$ & 156,41 \\
\hline \multirow{2}{*}{ Materials constans } & $\mathrm{E}$ & $\begin{array}{l}7.03 \times 10^{3}\left[\mathrm{kG} / \mathrm{mm}^{2}\right] \text { for } \mathrm{Al} \\
21 \times 10^{3}\left[\mathrm{kG} / \mathrm{mm}^{2}\right] \text { for } \mathrm{Fe}\end{array}$ & $\mathrm{S} 1=1.28 \mathrm{E}-6[1 / \mathrm{MPa}]$ \\
\hline & $v$ & $\begin{array}{c}0.345 \text { for } \mathrm{Al} \\
0.28 \text { for } \mathrm{Fe}\end{array}$ & $\mathrm{S} 2=11.42 \mathrm{E}-6[1 / \mathrm{MPa}]$ \\
\hline $\begin{array}{l}\text { Penetration depth of X- } \\
\text { rays }\end{array}$ & & $\begin{array}{l}\approx 26 \mu \mathrm{m} \text { for } \mathrm{Al} \text { and } \approx 13 \mu \mathrm{m} \\
\text { for } \mathrm{Fe}\end{array}$ & $\approx 10 \mu \mathrm{m}$ for $\mathrm{Fe}$ \\
\hline
\end{tabular}




\section{MATERIAL}

Tests were performed on samples of four different materials:

- from the wall of profile extruded in PA9 aluminium alloy, a flat specimen of $3 \times 9.5 \mathrm{~mm}$ cross-section was cut out. Using the X-ray method, residual stress was measured on the specimen surface and was reported to amount to $-11 \mathrm{MPa}$. The specimen was subjected to the effect of tensile forces, and additionally to the effect of compressive forces,

- from the ST12 steel a specimen of $2 \times 10 \mathrm{~mm}$ cross-section was prepared; in this specimen, the measured residual stress was $-62 \mathrm{MPa}$,

- from the HSS tool steel two specimens with cross-sections of $0.65 \times 9.75 \mathrm{~mm}$ each were prepared. In the first specimen, the value of the residual stress was $14 \mathrm{MPa}$; after grinding the surface of the specimen with sand paper, the residual stress increased to $-388 \mathrm{MPa}$.

The second sample showed the presence of the residual stress of $33 \mathrm{MPa}$. After grinding the surface of the specimen with sand paper, the residual stress increased to -177 MPa. After electrochemical etching of a layer of approximately $0.03 \mathrm{~mm}$ thickness, at a selected point, the measured residual stress assumed the value of $2.4 \mathrm{MPa}$.

Measurements of stress under load were carried out at two points, i.e. at the point where the surface of the sample was only ground, and at the point where the surface was ground and electrochemically etched,

- from the S235J2 steel a specimen of $6 \times 15 \mathrm{~mm}$ cross-section was prepared. The residual stress measured on the surface of the specimen by X-ray method amounted to $-56 \mathrm{MPa}$, and after the removal by electrochemical etching of a $0.1 \mathrm{~mm}$ thick layer, the residual stress amounted to $+25 \mathrm{MPa}$.

In all specimens, stresses were measured in the direction of the operating tensile forces.

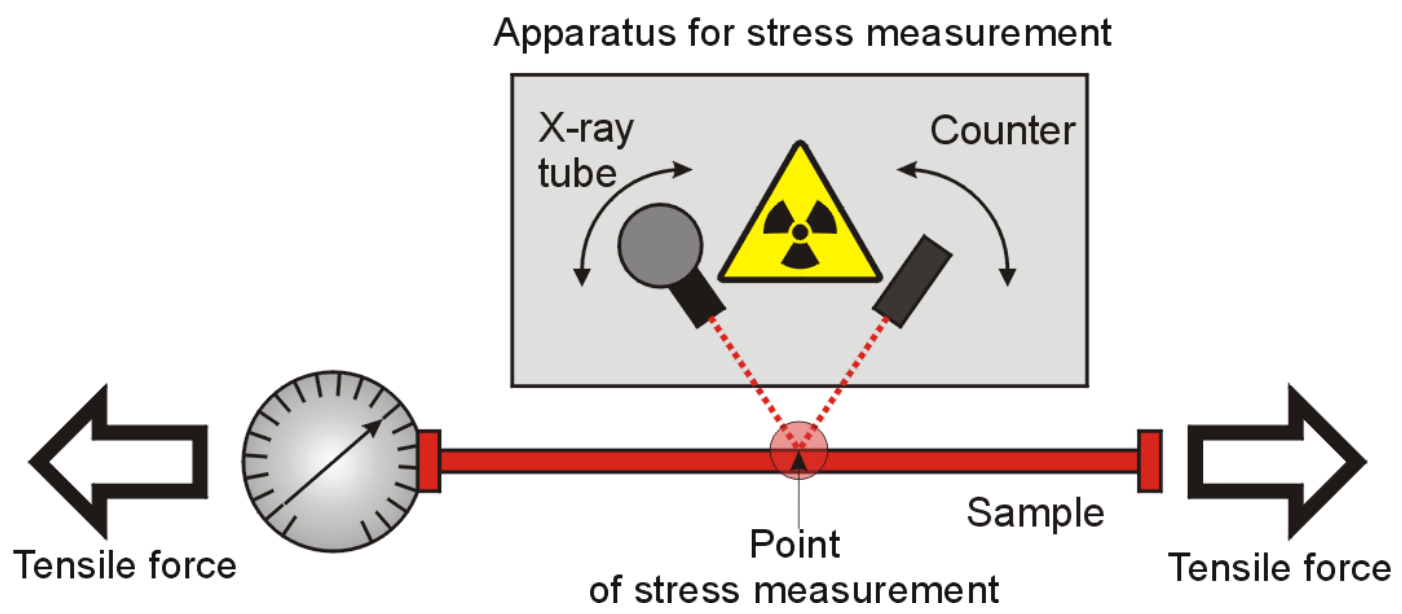

Fig. 3. Schematic representation of the $X$-ray stress measurement technique as performed on a specimen under the effect of constant load 

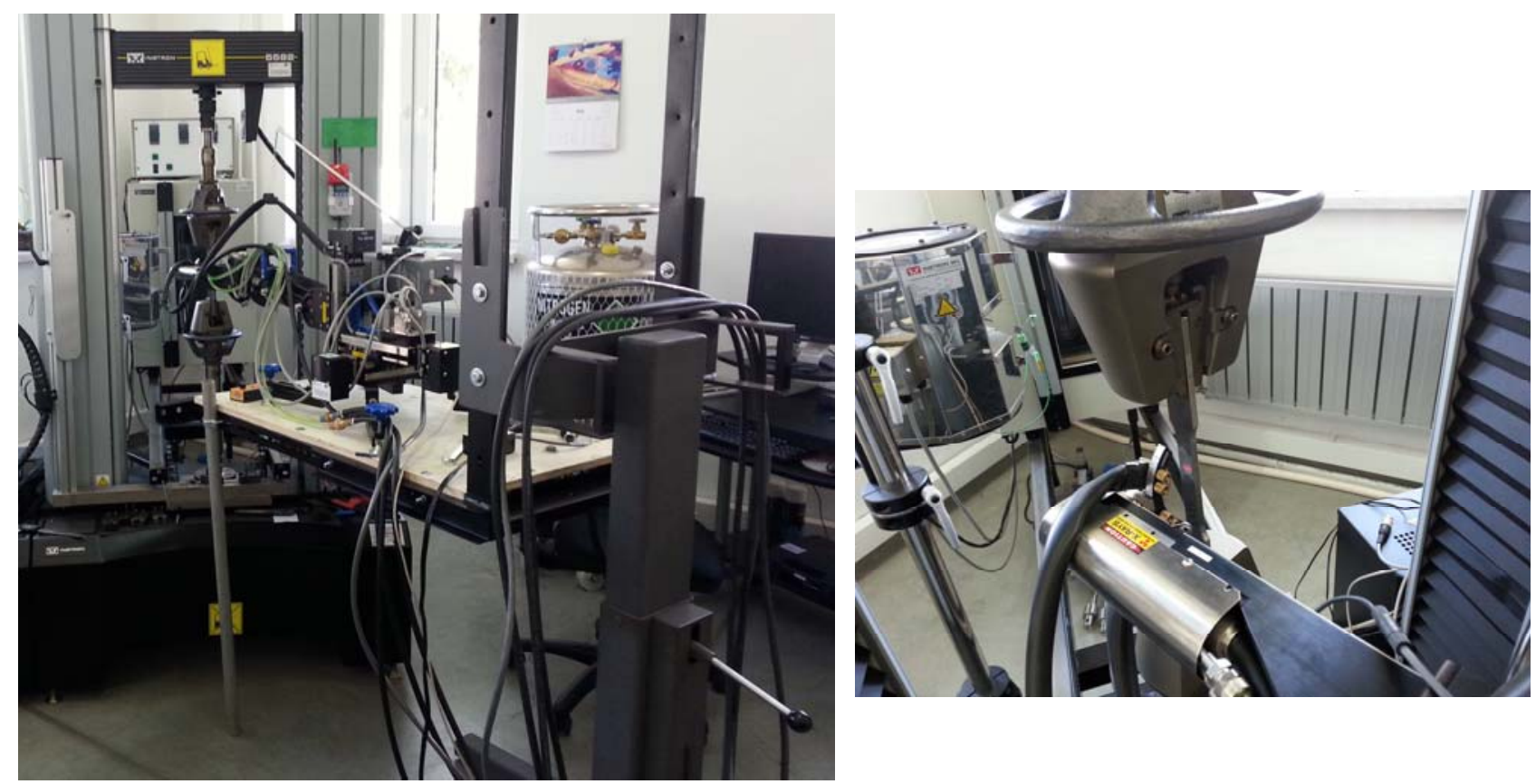

Fig. 4. Stress measurement by the X-ray method using a PROTO iXRD apparatus and specimen stretched on an Instron 5582 machine

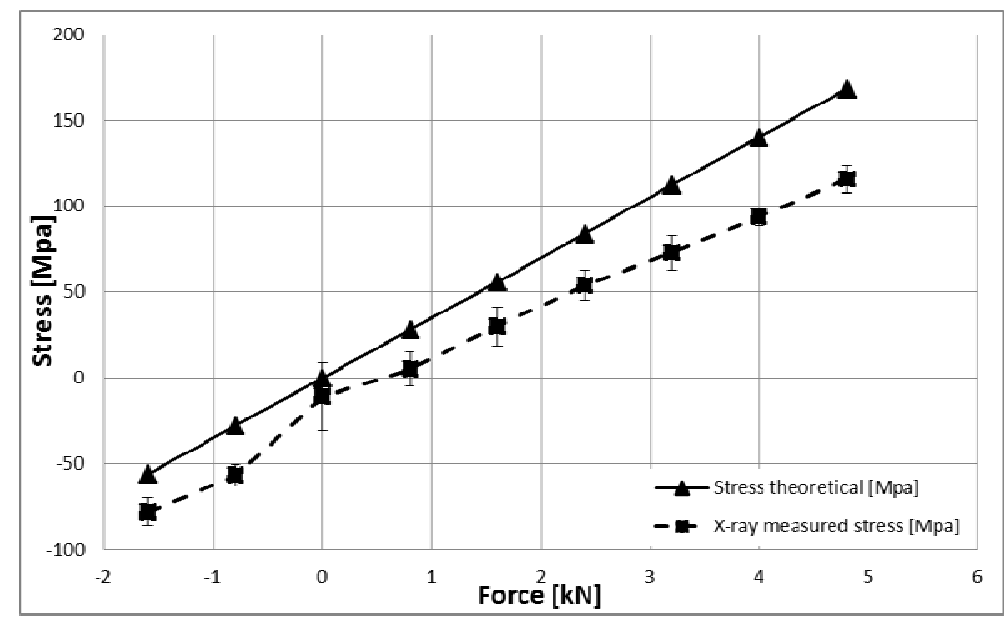

Fig. 5. Graph showing tensile force-dependent stress variations in the aluminium alloy specimen 


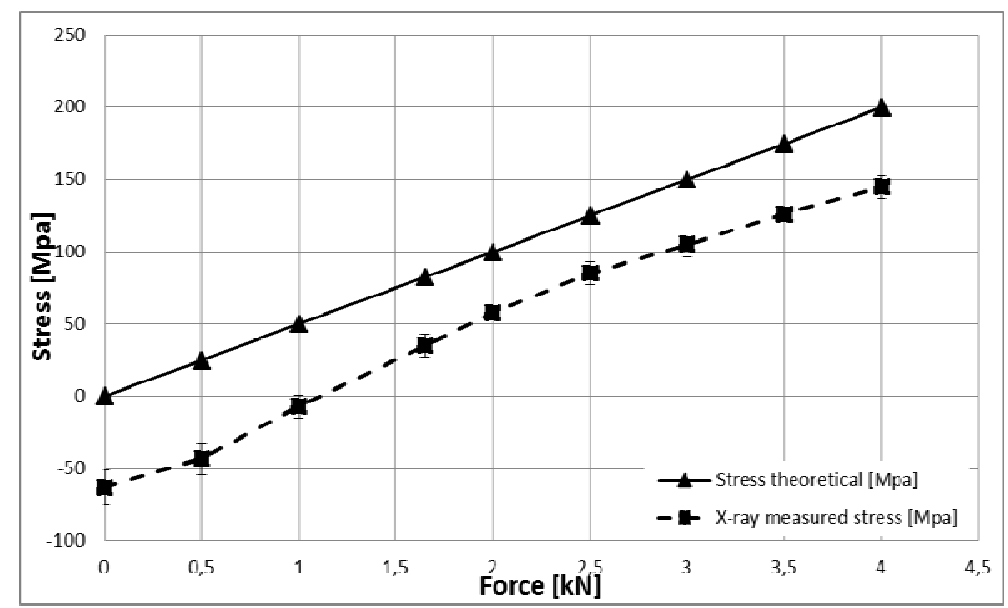

Fig. 6. Graph showing tensile force-dependent stress variations in the ST12 steel specimen

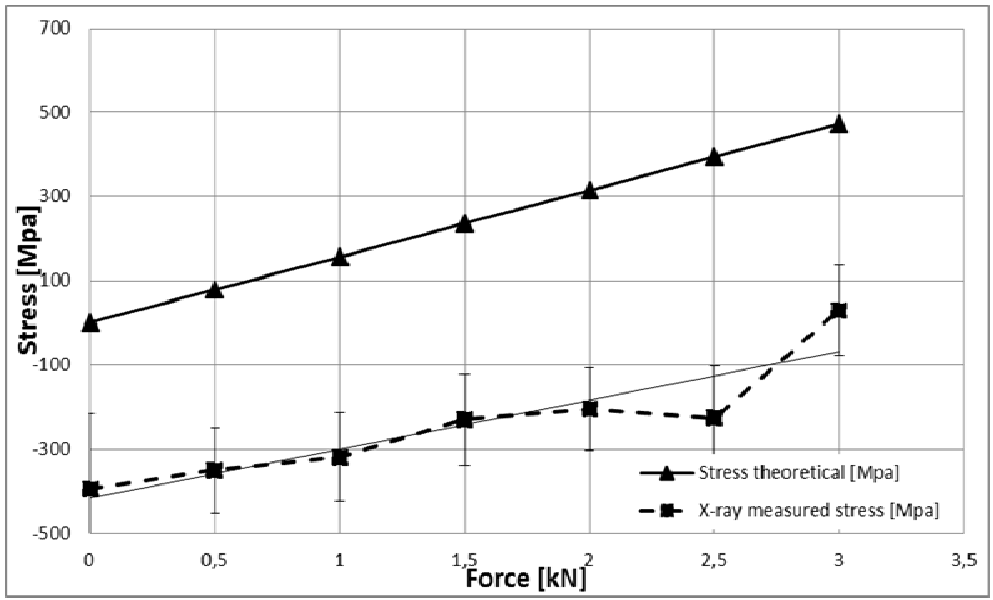

Fig. 7. Graph showing tensile force-dependent stress variations in the HSS steel specimen after surface grinding with sand paper

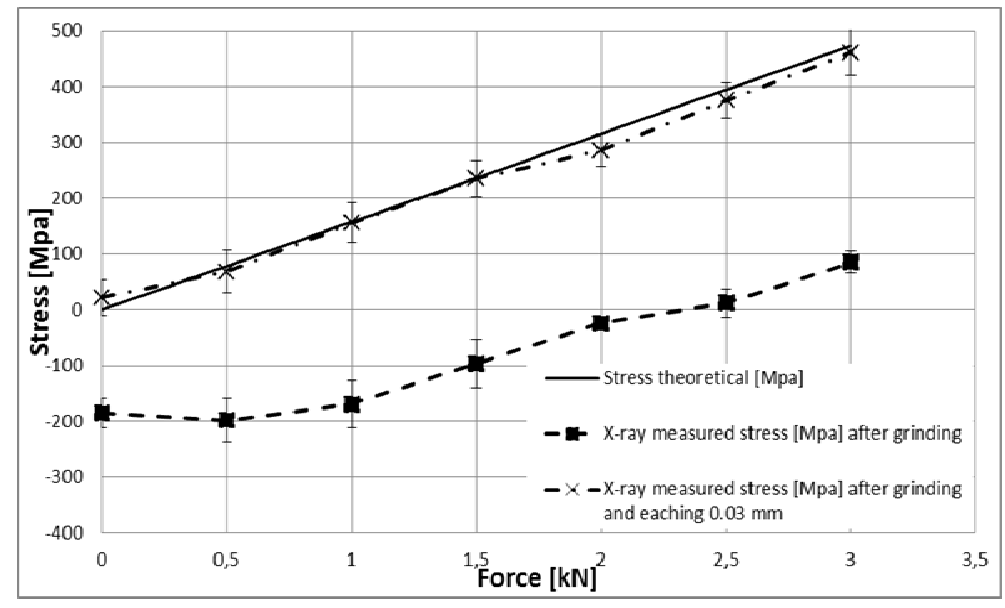

Fig. 8. Graph showing tensile force-dependent stress variations in the HSS steel specimen after surface grinding with sand paper and electrochemical etching of a $0.03 \mathrm{~mm}$ thick layer 


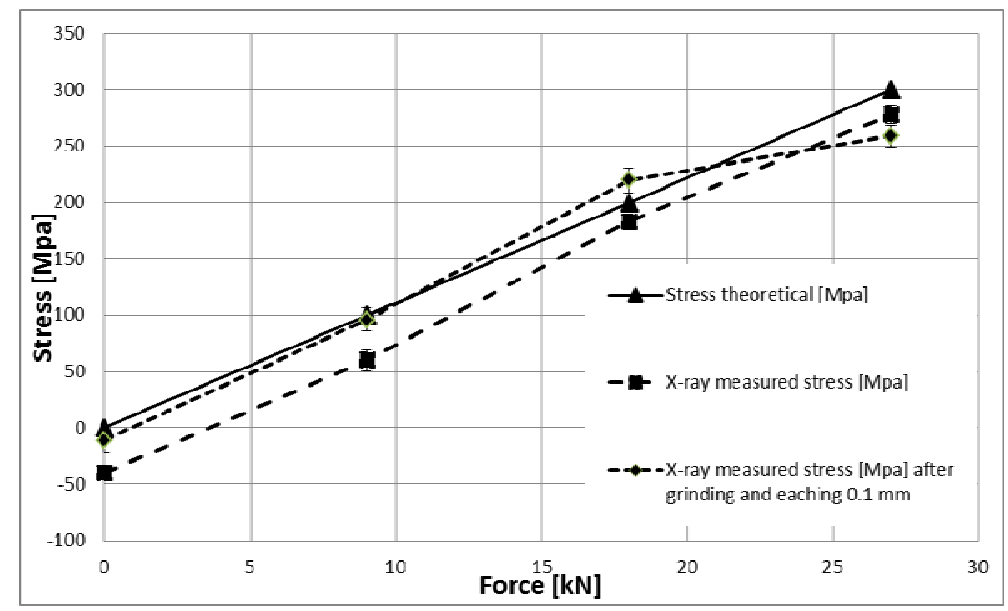

Fig. 9. Graph showing stress variations in the S235J2 steel specimen stretched on an INSTRON 5582 machine

\section{DISCUSSION}

As follows from the plotted graphs, in all the examined specimens, the X-ray measured stress values were either close to the theoretical values resulting from simple calculation of a ratio between the force acting on a specimen and the specimen cross-section (Figs. 5 and 8 for the point after electrochemical etching), or revealed a similar character of changes. The X-ray measured stress values different from the corresponding theoretical values were shifted by a value constant for a given specimen and close to the value of residual stress measured by the X-ray technique in unloaded specimens.

Close examination of graphs presented in Figures 7 and 8 shows that grinding of the specimen surface with sand paper introduces additional stresses to the specimen surface, which not only shift the values measured by X-rays, but also disturb the linear character of changes in these values. It was also noted that electrochemical polishing of the specimen surface shifts the stress values practically to the level of the corresponding theoretical values, which is consistent with previous observations [15].

\section{CONCLUSIONS}

- Stress measurements taken by the $\sin ^{2} \Psi$ X-ray method in aluminium and steel specimens loaded with the external stress of preset value confirmed close relationship between the stress values measured by the X-ray method and those actually present in the examined material.

- Using portable apparatus for the stress measurement (PSF Strainflex 2M, PROTO iXRD) it is possible to measure stresses occurring in the components of finished metal structures without damage done to this structure and without the need to use standard reference samples.

\section{ACKNOWLEDGMENTS}

Part of this work has been performed under the Project PBS1/A9/14/2012, supported by The National Centre for Research and Development (Poland) 


\section{REFERENCES}

1. Kula E., Weiss V.: Residual Stress and Stress Relaksation. Plenum Press New York,1982.

2. Kokosza A.: Application of the method magnetic Barkhausen noise measurement to evaluate the stress in steels, [in Polish]. Seminar on Methodological problems of residual stress measurement, Poznań 1994.

3. Noyan I.C., Cohen J.B.: Residual stress measurement by diffraction and interpretation, SpringerVerlag New York, 1987.

4. Pszonka A., Ziaja J.: X-ray stress measurement methods [in Polish]. Scientific Papers of the Institute of Materials Science and Engineering Wroclaw University of Technology, Wrocław 1971.

5. Lech-Grega M., Szymański W.: The use of X-ray residual stress measurement methods in nondestructive testing. [in Polish]. Scientific Session XVI Shipbuilders, part II, Szczecin-Dziwnówek 1994.

6. Lech-Grega M., Kusnerż J., Szymański W.: Residual stresses in welded joint parts of an alloy $\mathrm{AlZnMg}$, [in Polish], VII Conference "Non-ferrous metals in the shipbuilding industry", Szczecin - Międzyzdroje 1996.

7. Lech-Grega M., Szymański W.: X-Ray Residual Stress Measurement in 7020 Alloy Welded Jionts, 2003 TMS 132nd Annual Meeting \& Exhibition, San Diego, California, USA.

8. Lech-Grega M., Mazurkiewicz K., Szymański W.: Fatigue of material and the state of residual stress in the welded joints of an alloy AlZnMg, [in Polish]. National Conference selection and operation of engineering materials, Jurata 22-25.09.1997

9. Lech-Grega M., Kusnerż J., Szymański W.: Residual stresses in welded joint parts of an alloy AlZnMg, [in Polish]. VII National Conference - Nonferrous Metals in the Shipyard Industry; Międzyzdroje-Szczecin, 12-14 September 1996, Matt. Conf. 115-122.

10. Fajkiel L., Lech-Grega M., Szymański W.: Residual stresses in the surface layer of pressure forms under the influence of impacts of the molten aluminum, [in Polish]. Research Conf. - New Materials - New Technologies in The Ship and Machine Industry Szczecin-Swinoujscie September 1998.

11. Jurcius A., Valiulis A.V., Cernasejus O., Kurzydłowski K.J., Jaskiewicz A., Lech-Grega M.; Influence of wibratory stress relief on residual stresses in weldment and mechanical properties of structural steel joint; Vibromechanika, Journal of Vibroenergineering, March 2010, vol. 12, 133 141

12. Szymański W., Lech-Grega M., Gawlik M.: Evaluation of residual stresses in the layer of carburized gears, [in Polish]. IMN Report nr 7066/II/2013.

13. Szymański W.: Development of a method to evaluate the effectiveness of large-scale processing of cast iron EN-GJS-500-7, [in Polish]. Report IMN nr 7255/14.

14. Szymański W., Lech-Grega M., Gawlik M.: Assessment of changes in the state of stress in the strip of stainless steel in the process of straightening, [in Polish]. IMN Report nr 7254/14

15. Lech-Grega M., Kłyszewski A.: Strainflex apparatus PSF-2M for measuring residual stress and retained austenite, [in Polish]. Hutnik 6, 1991. 